Iğdır Üniversitesi Fen Bilimleri Enstitüsü Dergisi, 12(1): 317-323, 2022

Journal of the Institute of Science and Technology, 12(1): 317-323, 2022

ISSN: 2146-0574, eISSN: 2536-4618

Kimya / Chemistry

DOI: 10.21597/jist.978327

Araştırma Makalesi / Research Article

Geliş tarihi / Received:03.08.2021

Kabul tarihi / Accepted:11.10.2021

Atıf İçin: Arıkan Ölmez N, 2022. Asiklik imitlerin mikrodalga destekli sentezi. Iğdır Üniversitesi Fen Bilimleri Enstitüsü Dergisi, 12(1): 317-323.

To Cite: Arıkan Ölmez N, 2022. Microwave-assisted synthesis of acyclic imides. Journal of the Institute of Science and Technology, 12(1): 317-323.

\title{
Microwave-Assisted Synthesis of Acyclic Imides
}

\section{Nevin ARIKAN ÖLMEZ}

\begin{abstract}
Imides are an important class of compounds found in the structure of many biologically active and natural compounds. Imides are also important starting materials used in the synthesis of many heterocyclic compounds. Therefore, the synthesis of these compounds has attracted considerable attention and several innovative methods have been developed. Herein, the synthesis of acyclic imides has been reported from nitriles and carboxylic anhydrides in the presence of catalytic amounts of ptoluenesulfonic acid (PTSA) or $\mathrm{H}_{2} \mathrm{SO}_{4}$ under microwave irradiation. The reaction has proceeded in better yields with PTSA. When sulfuric acid was used, the product was obtained in lower yields since the degradation was increased. This new microwave-assisted method is compared with conventional heating, and the other methods, reported in the literature. The main advantages of this procedure are shorter reaction times, easier work-up, and good yields.
\end{abstract}

Keywords: Acyclic imide, nitrile, carboxylic anhydride, microwave-assisted synthesis 


\section{INTRODUCTION}

Imides are diacyl derivatives of ammonia or a primary amine, and these compounds are commonly found in many natural products and bioactive compounds (Maruyama et al.,1975; Ding et al., 2008). Many drugs containing the imide group exhibit so many different biological activities such as immunosuppressants (Koehn et al., 1992), cytotoxic anticancer agents (Pettit et al., 1989), antibiotics (Nakamura et al., 1974) and antifeedans (Nagle et al., 1996). Also, imides are important precursors in the synthesis of nitrogen-containing heterocyclic compounds (Flitsch et al., 1983, 1990; Lee et al., 2012).

Unlike cyclic imides, a few methods have been reported for the synthesis of acyclic imides. Generally, acyclic imides are synthesized by the reaction of amides with carboxylic acid and their derivatives as esters, anhydrides, and acyl chlorides (Wheeler et al., 1970; Challis et al., 1970; Davidson and Skovronek., 1958; Hurd and Prapas, 1959; Durrell et al., 1963). The other methods for the synthesis of acyclic imides are aminocarbonylation of aryl bromides (Schnyder and lndolese, 2002), reaction of azalactones with oxygen and palladium (Bates et al., 1984), oxidation of amides with ruthenium tetroxide (Tanaka et al., 1987), reaction of deprotonated amides with pentafluorophenyl esters (Merrit et al., 1998), reaction of amides with N,N-bis(trimethylsilyl)formamides (Kantlehner et al., 1978), $\alpha, \alpha, \alpha-$ trichloromethylcarbonyl compounds (Atanasov et al., 1990), diketene (Yamamoto et al., 1981) or vinyl esters (Seiller et al., 1995). In recent years, acyclic imides have been synthesized from oxidation of secondary amides with hypervalent iodine reagent DMP (Dess-Martin periodinane) (Nicolaou and Mathison, 2005), oxidation of N-benzylamides with selectfluor and copper bromide (Jin et al., 2011) or by using copper catalyst TBHP/TEMPO system (Yu et al., 2015), reaction of amides with carboxylic anhydrides precense of sulphuric acid by microwave irradiation (Lee et al., 2012), direct coupling of $\mathrm{NH}$-amides with methylarenes under iodine/aqueous TBHP conditions (Aruri at al., 2016), oxidative cleavage of C-C double bonds of enamides by the combination of hypervalent iodine (III) and $\mathrm{TMSN}_{3}$ (Liu et al., 2017), oxidations of $\mathrm{N}$-alkylamides by using oxone as the oxidant in the presence of a catalytic amount of $\mathrm{KBr}$ in $\mathrm{H}_{2} \mathrm{O} / \mathrm{CH}_{2} \mathrm{Cl}_{2}$ under irradiation by an white LED (Mei et al., 2018).

Since the first reports in 1986 (Gedey et al., 1986; Giguere et al., 1986) the use of the microwave heating technique has become an essential tool in all areas of organic synthesis. The microwave mediated organic reactions are environmentally friendly, safe, rapid, and high yield compared to conventional methods.

The synthesis of acyclic imides from the reaction of nitriles with acyclic anhydrides, in the presence of, silica sulfuric acid (Habibiet et al., 2007), tungtophosphoric acid under microwave irradiation (Mohammadpoor-Baltork et al., 2011) or p-toluenesulfuric acid by ultrasound-assisted (Nasresfahani et al., 2012) have been reported previously. Herein we report a microwave-assisted method for the synthesis of acyclic imides from nitriles and carboxylic anhydrides by using PTSA or $\mathrm{H}_{2} \mathrm{SO}_{4}$ as a catalyst (Figure 1).

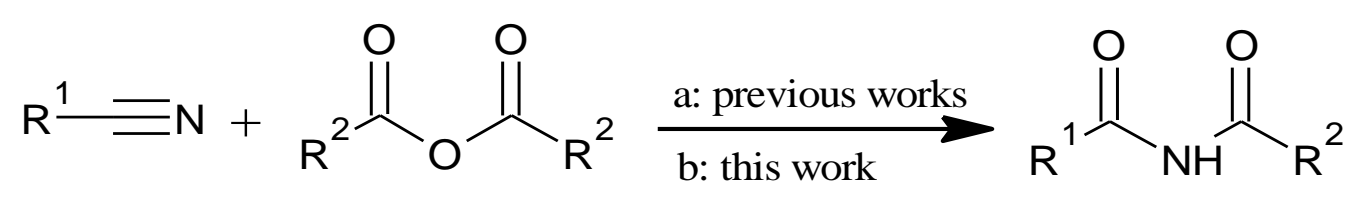

a) A: Silica sulfuric acid (Habibi et al., 2007), B: tungtophosphoric acid $\left(\mathrm{H}_{3} \mathrm{PW}_{12} \mathrm{O}_{40}\right)$ under microwave irradiation (Mohammadpoor-Baltork et al., 2011), C: p-toluenesulfuric acid (PTSA) by ultrasound-assisted (Nasr-esfahani et al., 2012)

b) PTSA and $\mathrm{H}_{2} \mathrm{SO}_{4}$ under microwave irradiation

Figure 1. Methods for the preparation of imides from nitriles and carboxylic anhydrides 


\section{MATERIALS AND METHODS}

\section{Materials}

Melting points were determined in Electrothermal 9100 melting point apparatus and are uncorrected. Infrared spectra were recorded on Spectrum Two (Perkin Elmer, USA) FT-IR spectrometer in ATR and the wave numbers were given in $\mathrm{cm}^{-1}$. NMR spectra were recorded using 400-MR NMR spectrometer (Agilent Technologies, USA). All of the microwave-assisted reactions was carried out with Discover System 908010 (Cem Corporation) All solvents and reagents were commercially available. Aluminum backed silica gel plates (Merck Kiesgel 60 F-254) were used for thin-layer chromatography (TLC).

\section{Experimental Procedure}

A mixture of nitrile (1 $\mathrm{mmol})$, carboxylic anhydride ( $2 \mathrm{mmol}$ ) and PTSA (30 mol \%, $0.3 \mathrm{mmol}$ ) (or concantrared $(98 \%, \mathrm{~d}=1.84 \mathrm{~g} / \mathrm{mL}) \mathrm{H}_{2} \mathrm{SO}_{4}, 2$ drops) was placed in a sealed tube and heated at $110^{\circ} \mathrm{C}$ in silicon bath or irradiated under microwave at $100^{\circ} \mathrm{C}\left(80^{\circ} \mathrm{C}\right.$ for $\left.\mathrm{H}_{2} \mathrm{SO}_{4}\right)$. The reaction was monitored by TLC (ethyl acetate: hexan, 1:3). After the reaction was completed, the reaction mixture was cooled to room temperature. Chloroform was added to the reaction mixture and washed several times with water. The organic phase dried with $\mathrm{Na}_{2} \mathrm{SO}_{4}$ and the solvent was evaporated under reduced pressure. The crude product was purified by column chromatography using ethyl acetate : hexane (1:3 or 1:1) eluent system or crystallized from hexane.

All products were characterized by the comparison of their melting or boiling points, IR, and ${ }^{1} \mathrm{H}$ NMR spectra with those of authentic samples.

N-Acetylbenzamide(1): White solid, mp. 108-109 ${ }^{\circ} \mathrm{C}$ (109-110 ${ }^{\circ} \mathrm{C}$; Mohammadpoor-Baltork et al., 2011). FTIR (ATR) v, $\mathrm{cm}^{-1} ; 3270,1750,1676 .{ }^{1} \mathrm{H}$ NMR (400 MHz, $\left.\mathrm{CDCl}_{3}\right) \delta(\mathrm{ppm}): 2.63$ (s, 3H); 7.52$7.86(\mathrm{~m}, 5 \mathrm{H}) ; 8.63$ (brs, $1 \mathrm{H})$.

N-Acetyl-4-methylbenzamide (2): White solid, mp.113-114 ${ }^{\circ} \mathrm{C}\left(111-113{ }^{\circ} \mathrm{C}\right.$; Mohammadpoor-Baltork et al., 2011). FTIR (ATR) v, $\mathrm{cm}^{-1} ; 3262,1724,1681 .{ }^{1} \mathrm{H}$ NMR (400 MHz, $\left.\mathrm{CDCl}_{3}\right) \delta$ (ppm): 2.43 (s, $3 \mathrm{H}) ; 2.61(\mathrm{~s}, 3 \mathrm{H}) ; 7.26-7.31(\mathrm{~m}, 2 \mathrm{H}) ; 7.74-7.76(\mathrm{~m}, 2 \mathrm{H}) ; 8.76$ (brs, $1 \mathrm{H})$.

N-Acetyl-3-methoxybenzamide (3): White solid, mp. 78-79 ${ }^{\circ} \mathrm{C}\left(79-80{ }^{\circ} \mathrm{C}\right.$; Lee et al., 2012). FTIR (ATR) $v, \mathrm{~cm}^{-1} ; 3367,1670,1650 .{ }^{1} \mathrm{H}$ NMR $\left(400 \mathrm{MHz}, \mathrm{CDCl}_{3}\right) \delta(\mathrm{ppm}): 2.62$ (s, 3H); 3.96 (s, 3H); 7.497.50 (m, 2H); 7.58 (s, 1H); 7.74-7.76 (m, 2H); 9.23 (brs, 1H).

N-Acetyl-3,4-dimethoxybenzamide (4): White solid, mp. 165-168 ${ }^{\circ} \mathrm{C}$. FTIR (ATR) $\mathrm{v}, \mathrm{cm}^{-1}$; 3367, 1655, 1651. ${ }^{1} \mathrm{H}$ NMR (400 MHz, $\left.\mathrm{CDCl}_{3}\right) \delta(\mathrm{ppm}): 2.62$ (s, 3H); 3.92 (s, 3H); 3.95 (s, 3H); 7.45-7.57 (m, $2 \mathrm{H}) ; 7.76(\mathrm{~s}, 1 \mathrm{H}) ; 9.50$ (brs, $1 \mathrm{H}) .{ }^{13} \mathrm{C} \mathrm{NMR}\left(100 \mathrm{MHz}, \mathrm{CDCl}_{3}\right) \delta$ (ppm): 174.8, 170.7, 165.3, 153.2, 149.3, 124.4, 122.2, 110.2, 56.2, 55.9, 25.6.

N-Acetyl-4-chlorobenzamide (5): White solid, mp. $141-143{ }^{\circ} \mathrm{C}\left(136-137{ }^{\circ} \mathrm{C}\right.$; Mohammadpoor-Baltork et al., 2011). FTIR (ATR) v, $\mathrm{cm}^{-1} ; 3255,1683,1660 .{ }^{1} \mathrm{H}$ NMR (400 MHz, $\left.\mathrm{CDCl}_{3}\right) \delta$ (ppm): 2.61 (s, 3H); 7.47-7.49 (m, 2H); 7.82-7.85 (m, 2H); 8.99 (brs, 1H).

N-Acetyl-4-florobenzamide (6): White solid, mp. $114-115{ }^{\circ} \mathrm{C}\left(111-112{ }^{\circ} \mathrm{C}\right.$; Mohammadpoor-Baltork et al., 2011). FTIR (ATR) v, $\mathrm{cm}^{-1} ; 3285,1670,1604 .{ }^{1} \mathrm{H}$ NMR (400 MHz, $\left.\mathrm{CDCl}_{3}\right) \delta$ (ppm): 2.61 (s, 3H); 7.17-7.21 (m, 2H); 7.88-7.90 (m, 2H); 8.63 (brs, 1H).

N-Acetyl-3-nitrobenzamide (7): Yellow solid, mp. 194-195 ${ }^{\circ} \mathrm{C}\left(195-196{ }^{\circ} \mathrm{C}\right.$; Mohammadpoor-Baltork et al., 2011) FTIR (ATR) v, $\mathrm{cm}^{-1} ; 3071,1679,1600 .{ }^{1} \mathrm{H}$ NMR (400 MHz, $\left.\mathrm{CDCl}_{3}\right) \delta$ (ppm): 2.64 (s, 3H); 7.75-8.75 (m, 4H); 8.88 (brs, $1 \mathrm{H})$.

N-Acetylacetamide (8): White solid, mp. $76-77^{\circ} \mathrm{C}\left(73^{\circ} \mathrm{C}\right.$; Mohammadpoor-Baltork et al., 2011). FTIR (ATR) v, $\mathrm{cm}^{-1} ; 3168,1660,1598 .{ }^{1} \mathrm{H}$ NMR $\left(400 \mathrm{MHz}, \mathrm{CDCl}_{3}\right) \delta(\mathrm{ppm}): 2.31$ (s, 6H); 8.63 (brs, 1H). 
N-Benzoylbenzamide (9): White solid, mp. $148-149{ }^{\circ} \mathrm{C}\left(146-147{ }^{\circ} \mathrm{C}\right.$ Voorstad et al., 1985). FTIR (ATR) $v, \mathrm{~cm}^{-1} ; 3071,1678,1601 .{ }^{1} \mathrm{H}$ NMR (400 MHz, $\left.\mathrm{CDCl}_{3}\right) \delta(\mathrm{ppm}): 7.47-7.51(\mathrm{~m}, 4 \mathrm{H}) ; 7.61-7.64$ (m, 2H); 8.13-8.15 (m, 4H); 9.11 (brs, 1H).

N-Benzoyl-4-methylbenzamide (10): White solid, mp. 125-130 ${ }^{\circ} \mathrm{C}$ (Yu et al., 2015, melting point not available) FTIR (ATR) v, $\mathrm{cm}^{-1} ; 3270,1693,1670 .{ }^{1} \mathrm{H}$ NMR (400 MHz, $\left.\mathrm{CDCl}_{3}\right) \delta$ (ppm): 2.43 (s, 3H); 7.29-7.86 (m, 9H); 8.98 (s, 1H).

\section{RESULTS AND DISCUSSION}

Acyclic imides were prepared by the reaction of aromatic and aliphatic nitriles with carboxylic anhydride in the precense of p-toluenesulphonic acid (PTSA) or $\mathrm{H}_{2} \mathrm{SO}_{4}$ under microwave irradiation in good to excellent yields. The reaction of benzonitrile and acetic anhydride was chosen as the model for optimization of the reaction condition. For this purpose, the reaction of benzonitrile (1 eqv.) and acetic anhydride (2 eqv.) was carried out with both $\mathrm{H}_{2} \mathrm{SO}_{4}$ and PTSA in different temperatures in solvent-free condition (Table 1). The reaction was monitored by TLC. The reaction was completed within 5 min. As shown in Table 1, both sulfuric acid and PTSA catalyzed reaction proceeds in good to excellent yields. However, when $\mathrm{H}_{2} \mathrm{SO}_{4}$ was used, it was observed that the yield decreased due to increased degradation at high temperatures. Decomposition products have not been determined because the rate of degradation is very low. According to the results, the optimum temperature was determined as $80{ }^{\circ} \mathrm{C}$ for $\mathrm{H}_{2} \mathrm{SO}_{4}$ and $100{ }^{\circ} \mathrm{C}$ for PTSA.

Table 1. The preparation of imides under various reaction conditions $\mathrm{s}^{\mathrm{a}}$ under microwave irradiation.

\begin{tabular}{cccc} 
& \\
& & & \\
\hline Entry & Temperature $\left({ }^{\circ} \mathrm{C}\right)$ & $\mathrm{H}_{2} \mathrm{SO}_{4}$ & Yield $^{\mathrm{b}}(\%)$ \\
\hline 1 & $\mathbf{8 0}$ & $\mathbf{9 0}$ & PTSA \\
\hline 2 & 90 & 87 & 92 \\
\hline 3 & $\mathbf{1 0 0}$ & 80 & $\mathbf{9 5}$ \\
\hline 4 & 110 & 78 & 90 \\
\hline 5 & 120 & 77 & 88
\end{tabular}

a) Used benzonitrile $(1.0 \mathrm{mmol})$, acetic anhydride $(2.0 \mathrm{mmol})$ and PTSA $(30 \mathrm{~mol} \%)$, or conc. $\mathrm{H}_{2} \mathrm{SO}_{4} \quad(2 \mathrm{drops})$

b) Isolated yield

In order to study the generality of this procedure, other aromatic and aliphatic nitriles were reacted with carboxylic anhydrides under optimized conditions (Table 2). Regarding aromatic nitriles, the substituents of benzonitriles did not affect the reactivity of the reaction electronically and sterically. In general, benzonitriles with both electron-donating and electron-withdrawing groups reacted well with acetic anhydride. When PTSA was used as the acid catalyst, imides have been obtained in much better yields in the same conditions. Compared to the method in the literature (Nasr-Esfahani et al.,2012), products were obtained in a shorter time than the ultrasonic-assisted reaction in similar yields.

The reaction was also carried out under conventional heating in the silicone bath, and the results were compared (Table 3). As shown in Table 3, the synthesis of imides under microwave irradiation is more effective than conventional heating. The transformations under conventional heating were completed within 1-2 hours in average yields, while under microwave irradiation were completed within $5 \mathrm{~min}$ in good yields. 
Table 2. Scope of the reaction ${ }^{\mathrm{a}}$

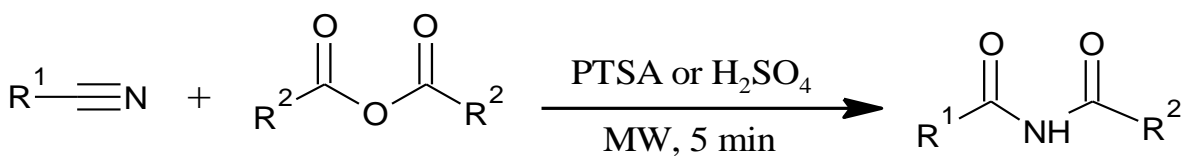

\begin{tabular}{|c|c|c|c|c|c|}
\hline \multirow{2}{*}{ Entry } & \multirow{2}{*}{$\mathbf{R}^{1}$} & \multirow{2}{*}{$\mathbf{R}^{2}$} & \multicolumn{2}{|c|}{ Yield $^{\mathrm{b}}(\%)$} & \multirow[b]{2}{*}{ MP (Exp. $/$ Lit. $\left.^{c}\right)\left({ }^{\circ} \mathrm{C}\right)$} \\
\hline & & & PTSA & $\mathrm{H}_{2} \mathrm{SO}_{4}$ & \\
\hline 1 & $\mathrm{C}_{6} \mathrm{H}_{5}$ & $\mathrm{CH}_{3}$ & 98 & 80 & $108-109 / 109-110$ \\
\hline 2 & $4-\mathrm{MeC}_{6} \mathrm{H}_{4}$ & $\mathrm{CH}_{3}$ & 97 & 78 & 113-114/111-113 \\
\hline 3 & $3-\mathrm{OMeC}_{6} \mathrm{H}_{4}$ & $\mathrm{CH}_{3}$ & 90 & 72 & 78-79/79-80 \\
\hline 4 & $3,4-(\mathrm{OMe})_{2} \mathrm{C}_{6} \mathrm{H}_{3}$ & $\mathrm{CH}_{3}$ & 95 & 77 & $165-168$ \\
\hline 5 & $4-\mathrm{ClC}_{6} \mathrm{H}_{4}$ & $\mathrm{CH}_{3}$ & 95 & 75 & 141-143/136-137 \\
\hline 6 & $4-\mathrm{FC}_{6} \mathrm{H}_{4}$ & $\mathrm{CH}_{3}$ & 92 & 74 & $114-115 / 111-112$ \\
\hline 7 & $3-\mathrm{NO}_{2} \mathrm{C}_{6} \mathrm{H}_{4}$ & $\mathrm{CH}_{3}$ & 72 & 65 & 194-195/195-196 \\
\hline 8 & $\mathrm{CH}_{3}$ & $\mathrm{CH}_{3}$ & 92 & 77 & $76-77 / 73$ \\
\hline 9 & $\mathrm{C}_{6} \mathrm{H}_{5}$ & $\mathrm{C}_{6} \mathrm{H}_{5}$ & 82 & 70 & $148-149 / 146-147$ \\
\hline 10 & $4-\mathrm{MeC}_{6} \mathrm{H}_{4}$ & $\mathrm{C}_{6} \mathrm{H}_{5}$ & 97 & 82 & $125-130 /$ not available \\
\hline
\end{tabular}

a) Used nitrile $(1.0 \mathrm{mmol})$, carboxylic anhydride $(2.0 \mathrm{mmol})$ and PTSA $(30 \mathrm{~mol} \%, 0.3 \mathrm{mmol})\left(\right.$ at $\left.100{ }^{\circ} \mathrm{C}\right)$ or conc. $\mathrm{H}_{2} \mathrm{SO}_{4}(2 \mathrm{drops})\left(\right.$ at $\left.80{ }^{\circ} \mathrm{C}\right)$

b) Isolated yield

c) References were given in the experimental section

Table 3. Effect of microwave irradiation for the reaction

\begin{tabular}{|c|c|c|c|c|c|c|}
\hline \multirow{2}{*}{ Entry } & \multirow{2}{*}{$\mathbf{R}^{1}$} & \multirow{2}{*}{$\mathbf{R}^{2}$} & \multicolumn{2}{|c|}{ Conventional heating } & \multicolumn{2}{|c|}{ Microwave irradiation $^{b}$} \\
\hline & & & Time (min) & Yield $^{\mathrm{c}}(\%)$ & Time $(\min )$ & Yield $^{\mathrm{c}}(\%)$ \\
\hline 1 & $\mathrm{C}_{6} \mathrm{H}_{5}$ & $\mathrm{CH}_{3}$ & 45 & 70 & 5 & 98 \\
\hline 2 & 4- $\mathrm{MeC}_{6} \mathrm{H}_{4}$ & $\mathrm{CH}_{3}$ & 55 & 82 & 5 & 97 \\
\hline 3 & $4-\mathrm{ClC}_{6} \mathrm{H}_{4}$ & $\mathrm{CH}_{3}$ & 50 & 75 & 5 & 95 \\
\hline 4 & $\mathrm{CH}_{3}$ & $\mathrm{CH}_{3}$ & 90 & 60 & 5 & 92 \\
\hline 5 & $\mathrm{C}_{6} \mathrm{H}_{5}$ & $\mathrm{C}_{6} \mathrm{H}_{5}$ & 90 & 50 & 5 & 82 \\
\hline
\end{tabular}

a) Used nitrile $(1.0 \mathrm{mmol})$, carboxylic anhydride $(2.0 \mathrm{mmol})$ and PTSA $(30 \mathrm{~mol} \%)$ in silicon bath at $110^{\circ} \mathrm{C}$

b) Used nitrile $(1.0 \mathrm{mmol})$, carboxylic anhydride $(2.0 \mathrm{mmol})$ and PTSA $(30 \mathrm{~mol} \%)$ under microwave irradiation at $100^{\circ} \mathrm{C}$.

c) Isolated yield

The synthesized products were purified by colon chromatography or recrystallization and characterized by the comparison of melting points and FTIR and NMR data from the literature. In the FTIR spectra of imide compounds, the characteristic -NH vibration bands were observed in the range of $3070-3300 \mathrm{~cm}^{-1}$, and the vibration bands of the two $\mathrm{C}=\mathrm{O}$ bonds were observed in approximately 1650 and $1750 \mathrm{~cm}^{-1}$. In the ${ }^{1} \mathrm{H}$ NMR spectra, the $\mathrm{NH}$ protons were observed as singlet in the range of 8.5-9.5 ppm as a broad signal. In the ${ }^{13} \mathrm{C}$ NMR spectra, the carbonyl carbons of imides were observed at about 170 and $175 \mathrm{ppm}$. Among the synthesized compounds, N-Acetyl-3,4-dimethoxybenzamide (4) is new, and ${ }^{1} \mathrm{H}$ and ${ }^{13} \mathrm{C}$ NMR spectra are given in Figure 1.

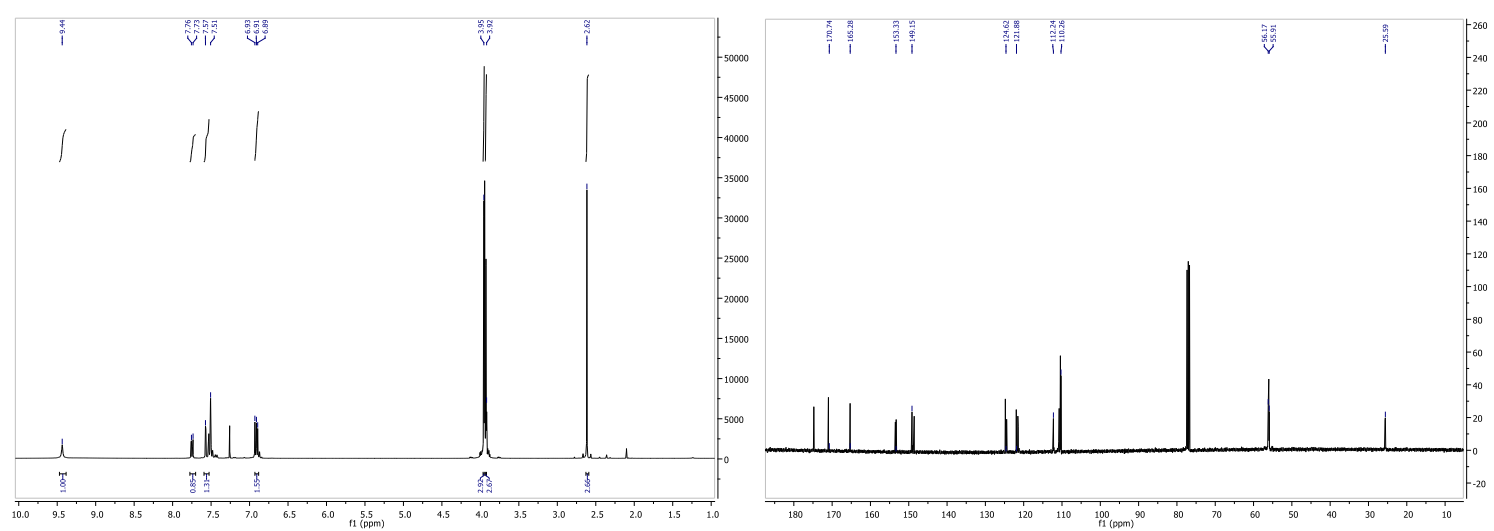

Figure 1. ${ }^{1} \mathrm{H}$ and ${ }^{13} \mathrm{C}$ NMR spectra of N-Acetyl-3,4-dimethoxybenzamide (4) 


\section{CONCLUSION}

As a result, an efficient and rapid synthesis of acyclic imides from the reaction of nitriles and carboxylic anhydrides presence of PTSA or $\mathrm{H}_{2} \mathrm{SO}_{4}$ as catalyst under microwave irradiation was reported. It was determined that PTSA is a more suitable catalyst than $\mathrm{H}_{2} \mathrm{SO}_{4}$ for this reaction. The products were obtained in a very short time in high yields compared with conventional heating and reported methods in the literature. This method will provide an easier way to synthesize of symmetrical or unsymmetrical acyclic imides from nitriles.

\section{Conflict of Interest}

The authors confirm that this article content has no conflict of interest

\section{REFERENCES}

Aruri H, Singh U, Kumar S, Kushwaha M, Gupta AP, Vishwakarma RA, Singh PP, 2016. I2/Aqueous TBHP-catalyzed coupling of amides with methylarenes/ aldehydes/alcohols: Metal-Free synthesis of imides. Organic Letters, 18: 3638-3641.

Atanassova IA, Petrov JS, Ognjanova VH, Mollov NM, 1990. $\alpha, \alpha, \alpha$-Trichloroketrylcarbonyl compounds as acylating reagents of amides. Synthetic Communications, 20: 2083-2090.

Bates RB, Fletcher FA, Janda KD, Miller WA, 1984. A convenient synthesis of unsymmetrical acyclic imides. The Journal of Organic Chemistry, 49: 3038.

Challis BC, Challis J, Zabicky J, (Ed.). 1970. The chemistry of amides. pp 759, J. Wiley and Sons, New York.

Davidson D, Skovronek H, 1958. The acylation of amides. Journal of the American Chemical Society, 80(2): 376-379.

Ding G, Jiang L, Guo L, Chen X, Zhang H, Che Y, 2008. Pestalazines and pestalamides, bioactive metabolites from the plant pathogenic fungus pestalotiopsis theae. Journal of Natural Products, 71: 1861-1865.

Durrell WS, Young JA, Dresdner RD, 1963. Fluorocarbon nitrogen compounds. IX. The reaction of nitriles with carboxylic acidsThe Journal of Organic Chemistry, 28: 831-833.

Flitsch W, Hohenhorst M, 1990. N-Protected 3-hydroxypyrroles. Liebigs Annalen Chemie, 397-399.

Flitsch W, Pandl K, Ruskamp P, 1983. Zur Umsetzung offenkettiger Imide mit 1ethoxycarbonylcyclopropyltriphenylphosphonium-tetraf luoroborat: Ein einfacher weg zu $1 \mathrm{H}-$ Pyrrol-3-carbonsäureestern. Liebigs Annalen Chemie, 529-534.

Gedye R, Smith F, Westaway K, Ali H, Baldisera L, Laberge L, Rousell J, 1986. The use of microwave ovens for rapid organic synthesis. Tetrahedron Letters, 27: 279-282.

Giguère R, Bray T, Duncan S, Majetich G, 1986. Application of commercial microwave ovens to organic synthesis. Tetrahedron Letters, 27: 4945-4948.

Habibi Z, Salehi P, Zolfigol MA, Yousefi M, 2007. A Novel one-pot synthesis of unsymmetrical acyclic imides. Synlett, 5: 812-814.

Hurd CD, Prapas AG, 1959. Preparation of acyclic imides. The Journal of Organic Chemistry, 24: 388392.

Jin Z, Xu B, Hammond GB, 2011. Copper mediated oxidation of amides to imides by Selectfluor. Tetrahedron Letters, 52: 1956-1959.

Kantlehner W, Fischer P, Kugel W, Möhring E, Bredereck H, 1978. N,N-Bis(trimethylsilyl)formamid und N,O-Bis(trimethylsilyl)imidsäureester; Struktur und chemische reaktivität. Justus Liebigs Annalen Chemie, 3: 512-527. 
Koehn FE, Longley RE, Reed JK, 1992. A Novel One-Pot Synthesis of unsymmetrical acyclic imides. Journal of Natural Products, 55: 613-619.

Lee J, Hong M, Jung Y, Cho EJ, Rhee H, 2012. Synthesis of 1,3,5-trisubstituted-1,2,4-triazoles by microwave-assisted $\mathrm{N}$-acylation of amide derivatives and the consecutive reaction with hydrazine hydrochlorides. Tetrahedron, 68: 2045-2051.

Liu G, Li Y, Sheng J, Wang XS, 2017. Oxidative cleavage of enamides with hypervalent iodine(III)/TMSN 3 under an air atmosphere. Synthesis, 49: 3968-3974.

Maruyama HB, Suhara Y, Suzuki-Watanabe J, Maeshima Y, Shimizu NJ, 1975. A new antibiotic, fumaramidmycin. I. Production, biological properties and characterization of producer strain. The Journal of Antibiotics, 28: 636-647.

Mei C, Hu Y, Lu W, 2018. Visible-Light-Driven oxidation of $N$-alkylamides to imides using oxone/ $\mathrm{H}_{2} \mathrm{O}$ and catalytic KBr. Synthesis, 50: 2999-3005.

Merrit B, Andrus WL, Keyes RF, 1998. Synthesis of mixed acyclic imides using pentafluorophenyl esters. Tetrahedron Letters, 39: 5465-5468.

Mohammadpoor-Baltork I, Tangestaninejad S, Moghadam M, Mirkhani V, Nasr-Esfahani M, 2011. Efficient synthesis of symmetrical and unsymmetrical acyclic imides catalyzed by reusable 12Tungstophosphoric acid under thermal conditions and microwave irradiation. Journal of the Iranian Chemical Society, 8 (2): 401-410.

Nagle DG, Paul VJ, Roberts MA, 1996. Ypaoamide, a new broadly acting feeding deterrent from the marine cyanobacterium Lyngbya majuscula. Tetrahedron Letters, 37: 6263-6266.

Nakamura H, Iitaka Y, Sakakibara H, Umezawa H, 1974. The molecular and crystal structure determination of bisanhydroalthiomycin by the x-ray diffraction method. The Journal of Antibiotics, 27: 894-896.

Nasr-esfahani M, Montazerozohori M, Filvan N, 2012. Ultrasound-assisted catalytic synthesis of acyclic imides in the presence of $p$-toluenesulfonic acid under solvent-free conditions. Journal of the Serbian Chemical Society, 77 (4): 415-421.

Nicolaou KC, Mathison CJN, 2005. Synthesis of imides, N-acyl vinylogous carbamates and ureas, and nitriles by oxidation of amides and amines with Dess-Martin periodinane. Angewandte Chemie International Edition, 44: 5992-5997.

Pettit GR, Kamano Y, Dufresne C, Cerny RL, Herald CL, Schmidt JM, 1989. Isolation and structure of the cytostatic linear depsipeptide dolastatin-15. The Journal of Organic Chemistry, 54: 6005-6006.

Schnyder A, Indolese AF, 2002. Synthesis of unsymmetrical aroyl acyl imides by aminocarbonylation of aryl bromides. The Journal of Organic Chemistry, 67: 594-597.

Seiller B, Heins D, Bruneau C, Dixneuf PH, 1995. Efficient preparations of acylamides, acylcarbamates and acylureas from alk-1-en-2-yl esters. Tetrahedron, 51: 10901-10912.

Tanaka Kl, Yoshifuji S, Nitta Y, 1987. Ruthenium tetroxide oxidation of $N$-acylated alkylamines: A new general synthesis of imides. Chemical and Pharmaceutical Bulletin, 35: 364-369.

Voorstad PJ, Chapman JM, Cocolas GH, Wyrick SD, Hall IH, 1985. Comparison of the hypolipidemic activity of cyclic vs. acyclic imides. Journal of Medicinal Chemistry, 28: 9-12.

Wheeler OII, Rosado O, Zabicky J (Ed.), 1970. The chemistry of amides. pp 335, J. Wiley and Sons, New York.

Yamamoto Y, Onishi S, Azuma Y, 1981. A new method for preparation of $N$-acetoacetyl-carboxamides. Synthesis, 122.

Yu H, Chen Y, Zhang Y, 2015. TBHP/TEMPO-mediated oxidative synthesis of imides from amides. Chinese Journal of Chemistry, 33: 531-534. 